\title{
APRENDIZAGEM ATIVA: ALUNO COMO PRODUTOR DE CONTEÚDO
}

\author{
MARINGÁ/PR JULHO/2018
}

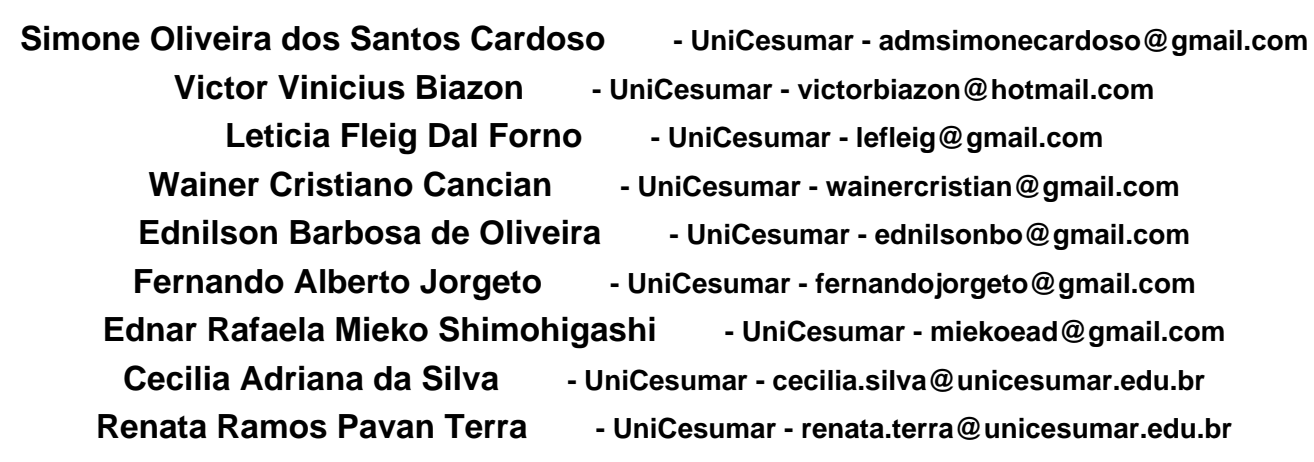

\author{
Tipo: Relato de Experiência Inovadora (EI) \\ Categoria: Métodos e Tecnologias \\ Setor Educacional: EDUCAÇÃO SUPERIOR
}

\begin{abstract}
RESUMO
As transformações no mercado de trabalho exigem que o sujeito esteja preparado e capacitado para agir ativamente. Neste contexto a formação profissional, que ocorre por meio da inserção no ensino superior, precisa inserir os processos práticos que se relacionam aos conceitos de atuação profissional. Frente ao desafio de uma formação qualificada para o mercado de trabalho este estudo aplica-se a uma instituição de ensino superior privada e ao contexto de educação à distância em um curso de engenharia, com o objetivo de investigar os impactos do processo de produção de vídeo por acadêmicos de graduação na disciplina de Promoções e Precificação para Lojas e Pontos de Venda. A atividade prática teve o propósito de facilitar e motivar os alunos na produção de sua atividade como forma de compartilhar seu conhecimento, experienciando a aprendizagem significativa. A pesquisa é qualitativa e quantitativa, tendo como percurso metodológico o levantamento bibliográfico em base de dados e a aplicação de um questionário o qual avaliou a percepção dos alunos após a realização do vídeo como atividade prática. Dessa forma, foi possível concluir que a realização da atividade prática foi relevante e positiva, tendo em vista que os alunos puderam produzir e editar um vídeo com um roteiro de entrevista elaborado pelo professor da disciplina, a qual procurava investigar as práticas promocionais realizadas pelo (a) empresário (a) no ponto de venda.
\end{abstract}

Palavras-chave: responsabilidade compartilhada; produção de vídeos; autonomia no aprendizado; educação a distância. 


\section{INTRODUÇÃO}

O mercado de trabalho têm sofrido diversas transformações com o desaparecimento de algumas profissões e com o surgimento de novas ocupações que exigem do profissional o desenvolvimento de habilidades que o tornem cada vez mais produtivos. Dentro desse contexto, as instituições de ensino precisam desenvolver nos estudantes as habilidades e competências que o mercado atual têm exigido. Para Damacena e Nascimento (2016), o estudante deverá ser capaz de aprender a utilizar os conceitos estudados e fazer as devidas adaptações às necessidades que o mercado de trabalho apresenta. Nesse sentido, os serviços educacionais serão contemplados somente através da presença e ativa participação do acadêmico. O envolvimento do aluno será capaz de despertar o maior interesse dele e torná-lo como um indivíduo ativo durante o aprendizado. Tendo em vista que a padronização de avaliação no ensino a distância por vezes não compreende a medida exata do que o aluno de fato compreende sobre os conceitos estudados, faz-se necessário que as instituições de ensino desenvolvam metodologias que colaborem para transmitir a aproximação fundamental entre os conceitos formais e o saber da experiência, de maneira a valorizá-los de forma igualitária esses saberes (FERNANDES JUNIOR; ALMEIDA; GOI, 2017). Como forma de avaliar e testar o que os alunos realmente aprenderam durante seus estudos na disciplina, formas diferenciadas de avaliação podem ser adotadas. Partindo desse contexto e das modernas visões do processo comunicacional, no qual o receptor passa a ser o protagonista do processo (MAZETTI, 2009; GALINDO, 2012 e VANDAL, 2014), da mesma forma, acredita-se que o aluno como produtor de conhecimento poderá ser estimulado a desenvolver a autonomia necessária para que ele se torne o protagonista do seu aprendizado.

A dinâmica decorrente das ferramentas tecnológicas, associada aos softwares e aplicativos que são atualizados constantemente, têm viabilizado que os alunos venham a compreender conceitos e produzir conteúdo dentro do contexto acadêmico (CARDOSO et al., 2017). O conteúdo gerado pelo próprio aluno auxilia no seu aprendizado e autonomia, cabe ao professor adotar métodos e estratégias pedagógicas que venham a promover a construção de conhecimento. Os alunos poderão ter um maior envolvimento com o aprendizado quando resolvem problemas que fazem parte da sua realidade, uma vez que o conhecimento será adaptável a realidade que o aluno vai encontrar no mercado de trabalho. Pois dessa forma existe o aprendizado do conceito na resolução de problemas na sua realidade. Nesse sentido, a presente pesquisa tem por objetivo averiguar os impactos do processo de produção de vídeo por acadêmicos de curso superior da área de gestão de uma instituição de ensino superior particular na modalidade a distância, na disciplina de Promoções e Precificação para Lojas e Pontos de Venda. Como forma de assegurar a aplicação das habilidades aprendidas na 
academia dentro do mercado de trabalho, essa atividade foi desenvolvida para motivar os alunos a produzirem o conteúdo e assim coproduzirem o aprendizado, tendo em vista que a responsabilidade compartilhada tende a auxiliar no desenvolvimento e comprovação das competências e habilidades que o mercado de trabalho tem exigido (DAMACENA; NASCIMENTO, 2016). Para atender ao objetivo frente ao contexto descrito, logo a seguir será apresentado o referencial teórico, o qual será sucedido pela metodologia utilizada no artigo. Por fim, serão apresentados os resultados e discussões, bem como as referências pesquisadas.

\section{APRENDIZAGEM ATIVA E A RESPONSABILIDADE COMPARTILHADA}

A educação na modalidade a distância $(\mathrm{EaD})$ evidencia características que auxiliam a superar algumas formas de exclusão (SOUSA; MOITA; CARVALHO, 2011). O estudante dessa modalidade terá condições de ultrapassar as barreiras do espaço e tempo, uma vez que ao estar conectado à rede, através da internet, poderá receber informações, realizar pesquisas e até mesmo produzir conhecimento. A flexibilidade existente nessa modalidade de ensino possui diversos entendimentos que envolve a flexibilidade do acesso, do ensino, aprendizagem e até mesmo da oferta de cursos, os quais anteriormente só poderiam ser disponibilizados presencialmente.

Dentro da EaD, o uso de ferramentas tecnológicas envolve o ambiente virtual de aprendizagem, o qual promove a interação entre aluno, professor e colegas de curso fundamentada na "transmissão da informação, na instrução, para a criação de ambientes de aprendizagem, onde o aluno realiza atividades e constrói o seu conhecimento" (SOUSA; MOITA; CARVALHO, 2011, p. 212). São tecnologias que possibilitam a interatividade, Galindo (2012, p. 69), diz que "o ato de comunicar é cada vez mais próximo de sua essência no sentido de tornar comum e compartilhar, diante da introdução contínua das tecnologias de relacionamento". Essa tecnologia de comunicação é que promove uma nova conexão do aluno com o conhecimento, a interação por meio dessas ferramentas acarreta na verificação de todos os papéis dos integrantes do processo de ensino e aprendizagem, assim como das metodologias usadas na promoção da aprendizagem.

Para se alcançar a aprendizagem, o aluno deve ser estimulado e motivado a ter uma maior autonomia e melhorar o desenvolvimento de habilidades que serão fundamentais para o melhor desempenho de suas funções no mercado de trabalho, assim como na sua formação como cidadão. Nesse contexto, a aprendizagem ativa será importante para que as competências e habilidades do aluno sejam desenvolvidas, de forma que ele tenha condições de organizar o seu conhecimento de uma maneira que seja possível 
facilitar a sua recuperação e venha conseguir efetivar sua a devida aplicação. Para Marquesi e Silveira (2015, p. 140) a aprendizagem ativa consiste na

Introdução de atividades a serem realizadas pelos alunos no contexto do ensino tradicional e a promoção do envolvimento dos alunos no processo de aprendizagem, em contraposição a estratégias didáticas que não pressupõem um papel ativo do estudante no processo, considerando-o um mero receptor passivo de informação.

Esse tipo de aprendizagem estimula o aluno a extrapolar as atividades mais tradicionais no ensino que normalmente envolvem assistir aulas, fazer leituras de conceitos, escutar e realizar anotações. Cabe ao professor desempenhar o papel de mediador e facilitador do conhecimento, concedendo maiores responsabilidades aos alunos, para que estes tenham o entendimento de que são membros ativos de sua aprendizagem (DAMACENA; NASCIMENTO, 2016). A aprendizagem ativa está relacionada a coprodução ou responsabilidade compartilhada que aluno e professor podem desenvolver no sentido de alcançar os resultados almejados de aprendizagem, assim como o pensamento crítico, o resultado das médias finais da disciplina e como consequência, a sincronia que esse aprendizado resultará no desempenho desse aluno no decorrer de sua carreira profissional após concluir a graduação. A responsabilidade compartilhada segundo Damacena e Nascimento (2016, p. 18):

\footnotetext{
Salienta elementos sociais de aprendizagem. Por exemplo, na capacidade colaborativa em resolução de problemas, os alunos partilham conhecimento como ferramentas para alcançar processos mais profundos de aprendizagem e, em muitos casos, para também conseguir melhores resultados/notas. Isto é: a sua participação em discussões, diálogos e reflexões compartilhadas mutuamente resulta em uma melhor aprendizagem do aluno.
}

\section{A INOVAÇÃO NO PROCESSO DE ENSINO APRENDIZAGEM}

A educação a distância é uma realidade em franca expansão, porém há muito o que se construir e conscientizar para a promoção de ensino com qualidade. Sabendo que os consumidores/alunos dessa modalidade buscam flexibilidade de horários, é possível que a metodologia educacional ainda possa ser melhorada no sentido de promover mais interatividade. Tendo em vista a necessidade que o professor têm de investigar novas técnicas, métodos e recursos distintos para viabilizar ao aluno um aprendizado significativo e autônomo (FERNANDES JUNIOR; ALMEIDA; GOI, 2017), a proposição aos alunos para produzir e compartilhar vídeos torna possível a construção e participação ativa do aluno no processo de ensino e aprendizagem (FLECHER et al., 2017).

Nesse contexto de mudanças, a inovação é um conjunto de processos estratégicos relacionados ao desenvolvimento e renovação dos produtos, processos, serviços, modelos de gestão e de negócios que a organização oferece ao mercado, e as maneiras 
como o faz, de forma a obter vantagem competitiva (STOECKICHT, 2005, p.33) essa inovação deve ser pensada por parte das novas modalidades de ensino diante dos novos tempos. Já Porter (1985, p. 36) diz que inovação é um conjunto de melhorias na tecnologia e nos métodos ou maneiras de fazer as coisas. No processo de ensino e aprendizagem na educação a distância, cada instituição segue uma metodologia específica para avaliar seus alunos. Porém, acredita-se que há necessidade de vincular algumas transformações que oportunizem ao aluno utilizar suas experiências e sua busca pelo conhecimento para que possa aprender e também construir conteúdo, tornando-o um sujeito ativo com maior autonomia no processo de ensino e aprendizagem.

A utilização de recursos digitais podem ser aliados tanto do professor quanto do aluno para extrapolar os métodos e juntos desenvolverem uma relação de ensino no qual todos produzam conhecimento.Diante desse contexto de tecnologias a serviço da educação, iniciativas transformadoras precisam ser cada vez mais frequente. Para Fernandes Junior, Almeida e Goi (2017), será importante integrar as tecnologias e hipermídia dentro do contexto educacional, uma vez que a produção e compartilhamento de informações que são propagadas nas redes oferecem novos conhecimentos. A hipermídia será uma ferramenta audiovisual relevante nesse contexto de produção de conteúdo, tendo em vista que os alunos têm maior acesso à produção, edição e postagem de vídeos. A hipermídia através do vídeo pode ser uma prática relevante dentro do contexto educacional e de aprendizagem. Um das formas de utilização do vídeo como recurso educacional é do próprio aluno agir de forma ativa como produtor desse conteúdo. Essa maneira de utilização proporciona a construção de conhecimento, ao dar vez ao aluno de produzir conteúdo, assim como ver o vídeo que foi produzido por seus colegas, viabilizando a troca de experiências (SOUSA; MOITA; CARVALHO, 2011).

O professor como mediador do conhecimento têm a oportunidade de trabalhar o desenvolvimento de alguns fatores relevantes à formação do aluno durante a produção de vídeo (TORI, 2015), dentre eles podem ser destacados: Autonomia: caso o aluno não tenha algum sentimento de autonomia existe uma maior disposição ao acomodamento e desmotivação; Senso de competência: o aluno precisa se sentir competente para a realização de determinada atividade, algo que o motivará a executá- la; Relacionamento: é indispensável que o aluno tenha a percepção de que a sua atividade se relaciona com seu entorno, como sendo algo significativo para a sua vivência.

\section{METODOLOGIA DE ESTUDO}


No desenvolvimento do estudo foram utilizadas diversas técnicas de coleta de dados, incluindo inicialmente ampla pesquisa bibliográfica no portal de periódicos da Coordenação de Aperfeiçoamento de Pessoal de Nível Superior (Capes). O levantamento bibliográfico realizado no portal de periódicos da Capes apresentou seis resultados para as palavras "aprendizagem ativa" e "ensino a distância" com a determinação da data de publicação para os últimos cinco anos, o que compreende o período de 2014 a 2018. Dentro do mesmo período de publicação foram pesquisados os termos "autonomia no aprendizado" e "responsabilidade compartilhada", resultando em três artigos, para os termos "responsabilidade compartilhada" e "produção de vídeo" foram dezenove artigos.

A pesquisa foi estruturada sob forma descritiva qualitativa sendo a coleta de dados baseada no seguintes processos: Qualitativa com a descrição da proposta de atividade, aplicação e também o feedback dos envolvidos. Cuja coleta se deu por análise documental no ambiente virtual de aprendizagem e com o envio de questionário por emails aos alunos cujas respostas (por adesão durante o mês de março de 2018) permitem a percepção de aprendizado.

\section{APRESENTAÇÃO E DISCUSSÃO DOS RESULTADOS}

O aprendizado na disciplina de Promoções e precificação para lojas e pontos de venda tinham os seus estudos direcionados para um objetivo maior dentro da sua realidade como gestor ou profissional da área do varejo. A ideia era que o aluno pudesse complementar seu conhecimento buscando referências reais no mercado que ele conhece, da sua cidade, do seu convívio e posteriormente tornar-se produtor de conteúdo que pudesse também contribuir com outros acadêmicos. A proposta avaliativa de produção do vídeo foi um dos critérios utilizados para a composição da média final do aluno na disciplina. Essa foi uma atividade dentro do material de avaliação prática de aprendizagem, a qual representa uma proposta avaliativa onde são adquiridos conhecimentos da referida disciplina dentro do seu contexto prático. Para o desenvolvimento do vídeo foram apresentadas as seguintes instruções: $1^{\circ}$ ) Produzir vídeo entre 2 a 5 minutos com o smartphone seguindo o roteiro de entrevista disponibilizado pelo professor. Realizar uma entrevista com gestor de loja apresentando os principais tipos de ações promocionais realizados pela empresa. $2^{\circ}$ ) Postar o vídeo no YouTube e enviar o link para a que o mesmo seja visualizado e avaliado.

O aluno teve a sua disposição um vídeo tutorial explicando como deveria realizar a postagem no YouTube, assim como um fórum para tirar dúvidas e adicionar contribuições relevantes ao desenvolvimento da atividade proposta. Considerando os 
critérios avaliativos nessa atividade, foram observados a imagem, o áudio, o clima criado durante a entrevista, a desenvoltura do aluno entrevistador, dentre os quais deveriam funcionar de maneira integrada e criar um ambiente harmonioso capaz de despertar interesse. Para Felcher et al. (2017, p. 8), o vídeo pode ser usado para o maior envolvimento do aluno no espaço educacional, assim como instigá-lo a "explorar suas habilidades em diversas ações que a sua produção proporciona". Para a gravação, edição e postagem do vídeo, os alunos deveriam pesquisar em seu município uma loja que desenvolvesse ações promocionais conforme o conteúdo estudado na disciplina. Depois deveriam contactar o (a) gestor (a) responsável e agendar entrevista para realizar a gravação. O processo dessa aprendizagem prática é descrito na Figura 1.

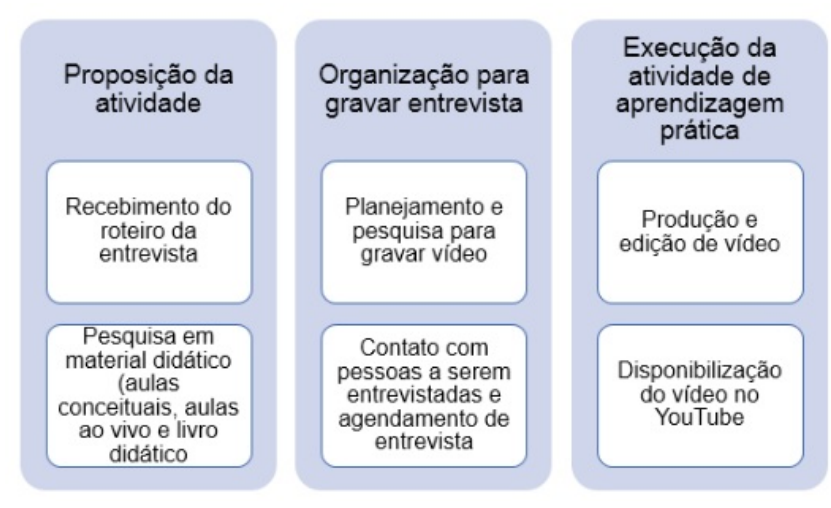

Figura1: Processo observado na atividade de aprendizagem prática.

Fonte: Adaptado de CARDOSO et al. (2017).

Durante o desenvolvimento de produção do vídeo, foi possível observar o maior interesse dos alunos quanto a essa utilização da tecnologia no seu processo de aprendizagem. Para Felcher et al. (2017, p. 8), ocorre uma preocupação dos alunos quanto ao entendimento de pesquisar, "qualificar-se, tendo em vista as necessidades impostas e o próprio desafio de produzir vídeos, uma metodologia um tanto incomum para eles”. Conforme os depoimentos recolhidos durante a aplicação dos questionários junto aos alunos sobre a execução da atividade prática, foi possível observar que os alunos se sentiram desafiados e que puderam perceber a importância da atividade quanto a sua vivência prática que o mercado apresenta, conforme fala de aluno "foi uma experiência muito diferente e muito boa, me ajudou muito no meu aprendizado. Não imaginava que teria essa capacidade, pois no início fiquei com medo de como fazer a entrevista. E quando terminei e postei o vídeo foi uma sensação de vitória e vi que realmente era capaz de prosseguir".

O aluno identificou que houve mudança no seu processo de aprendizagem ao produzir o 
vídeo, destacando que houve uma melhor identificação de como os conceitos estudados poderão ser desenvolvidos na prática. Conforme relato de aluno "essa experiência foi muito interessante, pois pude aprender de perto como os gestores de lojas lidam com essa parte dentro de um ponto de venda. Como meu trabalho permite conversar com vários comerciantes, posso tirar informações e observar como cada pessoa faz para promover sua loja. Foi incrível!" O referido processo avaliativo correspondeu a $15 \%$ da composição da nota final da disciplina, porém, observa-se que o aprendizado construído durante o processo de desenvolvimento da atividade prática foi algo relevante para os alunos, conforme os resultados coletados em questionário. Conforme Silva (2014) assegura, a elaboração de vídeos extrapola a sua finalidade inicial, que é a finalidade avaliativa, pois ela se mostra como um relevante meio de aprendizagem. A Figura 2 apresenta alguns dos vídeos que foram postados pelos alunos.
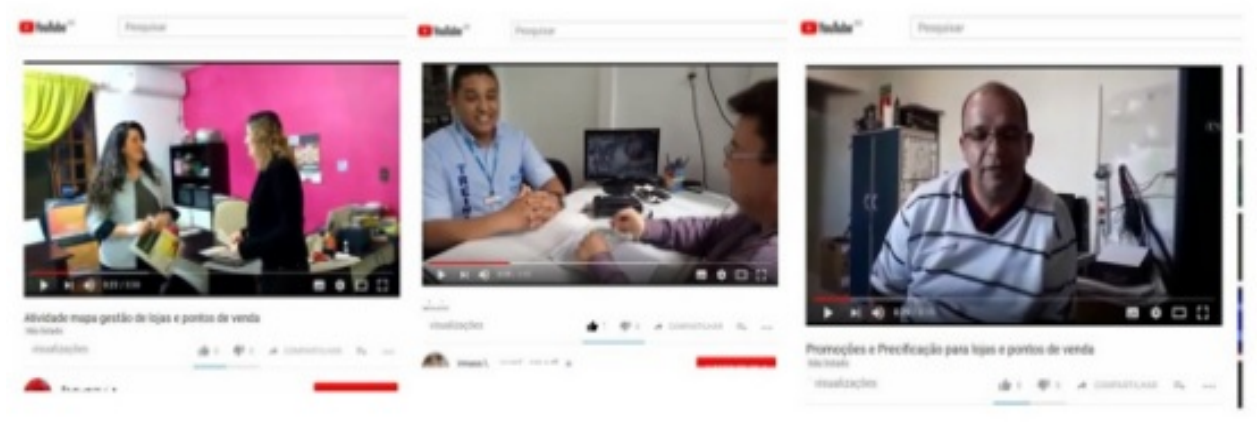

Figura 2: Vídeos produzidos pelos alunos na disciplina de Promoções e precificação para lojas e pontos de venda.

Fonte: Print do YouTube (2018).

Frente ao contexto apresentado, observa-se que houve êxito quanto a um dos principais objetivos a serem alcançados durante a execução da atividade avaliativa, que era a coprodução do aprendizado. Segundo Felcher et al. (2017), o mais relevante não é repetir aquilo que se ouviu, mas ter a capacidade de aplicar na sua vivência profissional e pessoal os conceitos estudados, ou seja, o aluno deverá definir com suas palavras aquilo que entendeu, utilizando-o em outros contextos, assim como relacioná-lo a outras situações.

\section{CONSIDERAÇÕES FINAIS}

A aplicação de aprendizagem prática através da produção de vídeo pelos alunos em processo avaliativo foi relevante ao aprendizado destes, conforme foi possível observar durante a realização do presente trabalho. Tendo em vista que os mesmos foram a 
campo e tiveram a oportunidade de ampliar o seu conhecimento prático e de como esses conceitos estudados na disciplina de Promoções e precificação estavam sendo aplicados na vivência de gestores e de lojas. Dessa forma, foi possível observar a existência da coprodução do aprendizado e de maior envolvimento do aluno no seu processo de aprendizagem.

A atividade proposta e observada, a qual foi objeto da presente pesquisa, viabilizou que os alunos verificassem na prática como acontece a aplicação dos conteúdo estudado nas aulas. Sendo assim, a metodologia utilizada na atividade prática teve uma avaliação positiva pelos alunos, uma vez que puderam fazer a ligação da teoria com a prática dentro do mercado de trabalho. Esses futuros profissionais poderão utilizar o aprendizado em outros contextos, relacionando-o com outras situações que o mercado de trabalho apresentará.

\section{REFERÊNCIAS}

CARDOSO, S. O. S.; et al. A utilização de metodologias ativas como instrumento de autonomia e forma de aprendizagem para o aluno do ensino a distância. In.: 23ํㅜㅇ Congresso Internacional ABED de Educação a Distância, 2017, Foz do Iguaçu. Anais. Foz do Iguaçu: CIAED, 2017 Doi: 10.1743/ciaed/XXIIICIAED.2017.00383 Disponível em: <https://goo.gl/CFvyzp>. Acesso em: 21 abr. 2018.

DAMACENA, C.; NASCIMENTO, T. M. Responsabilidade Compartilhada e sua Influência nas Atitudes de Estudantes de Administração de uma IES Privada de Porto Alegre. Administração: Ensino e Pesquisa, [S.I.], v. 17, n. 1, p. 9-32, abr. 2016. ISSN 2358-0917. Disponível em: <https://goo.gl/Lfd7YZ>. Acesso em: 20 abr. 2018.

FERNANDES JUNIOR, A. M.; ALMEIDA, S. C. D.; GOI, V. M. Hábitos midiáticos e aprendizagem - proposição de hipermídia para o ensino fundamental. Educação e Linguagem. São Paulo, v. 20, n. 2, p. 125-141, jul-dez 2017. ISSN: 2176-1043. Disponível em: <https://goo.gl/awYd6e>. Acesso em: 20 abr. 2018.

FLECHER, C. D. O.; et al. Produzindo Vídeos, Construindo Conhecimento: Uma Investigação Com Acadêmicos Da Matemática Da Universidade Aberta Do Brasil. PRedin - Revista Educacional Interdisciplinar. Disponível em: <https://goo.gl/u5uiDQ>. Acesso em: 20 abr. 2018.

GALINDO, Daniel dos Santos. Comunicação Mercadológica uma revisão conceitual in Comunicação Institucional e Mercadológica - Expansões conceitual e Imbricações 
temáticas, organizado por Daniel S. Galindo, São Bernardo do Campo: Editora metodista, 2012

MARQUESI, S. C.; SILVEIRA, I. F. Tecnologias da Informação e Comunicação como Suporte à Aprendizagem Ativa de Língua Portuguesa no Ensino Superior. Linha D’Água. São Paulo, v. 28, n. 1, p. 137-154, jun-2015 ISSN 2236-4242. Disponível em: < https://goo.gl/DT1iVJ>. Acesso em: 21 abr. 18

MAZETTI, H. M. Cultura participativa, espetáculo interativo: do "empoderamento" ao engajamento corporativo dos usuários de mídia. Intercom - XIV Congresso de Ciências da Comunicação na Região Sudeste. Rio de Janeiro, 2009. Disponível em <https://goo.gl/VYT9NU> Acesso: em 21 fev 2017.

PORTER, M. Estratégia Competitiva. 1 ed. Rio de Janeiro, Campus, 1985.

SILVA, J. P. A produção de vídeo estudantil na prática docente: Uma forma de ensinar. Tese (Doutorado) - Programa de pós-graduação em Educação, Faculdade de Educação, Universidade Federal de Pelotas, 2014.

SOUSA, R. P.; MOITA, F. M. C. S. C.; CARVALHO, A. B. G. (orgs.) Tecnologias digitais na educação. Campina Grande: EDUEPB, 2011. 276 p.

STOECKICHT, I. P. Gestão estratégica do capital humano - avaliando o potencial de inovação de uma empresa: estudo de caso. Dissertação (mestrado) apresentada a Universidade Federal Fluminense. Niterói, 2005. Disponível em: <https://goo.gl/1ks5U6> Acesso em: 20 abr 2018.

TORI, R. Tecnologia e Metodologia para uma Educação Sem Distância. Em Rede Revista de Educação a Distância, Porto Alegre, v. 2, n 2, p. 44-55, 2015. ISSN 2359-6082. Disponível em: <https://goo.gl/zJZEsw>. Acesso em: 20 abr. 2018.

VAN DAL, J. L. G. A Comunicação mercadológica na sociedade em rede: apropriação da cultura participativa pela publicidade. Dissertação (mestrado em Comunicação Social) -Faculdade de Comunicação da Universidade Metodista de São Paulo, São Bernardo do Campo, 2014. 